\title{
25594
}

\section{Building a Seismically Conditioned Geological Model from Vp/Vs Ratio Volume for Flow Simulation}

\begin{abstract}
A.G. William (ExxonMobil Exploration and Production Malaysia Inc), Y.C. Lye (ExxonMobil Exploration and Production Malaysia Inc) \& W.Y. Loh* (ExxonMobil Exploration and Production Malaysia Inc)
\end{abstract}

\section{SUMMARY}

This paper describes the use of high quality seismic data to condition a numerical geological model of the $\mathrm{T}$ field, forming the basis for resource assessment and performance prediction. The $\mathrm{T}$ field is located in the Malay basin and was discovered in 1979, approximately $200 \mathrm{~km}$ offshore Terengganu, Malaysia. The primary non-associated gas (NAG) accumulation in the field is found in the shallow A/B reservoirs. These reservoirs are found at approximately $700 \mathrm{~m}$ TVDss and consist of lower to middle Miocene siliciclastic sediments. 


\section{Introduction}

This paper describes the use of high quality seismic data to condition a numerical geological model of the $\mathrm{T}$ field, forming the basis for resource assessment and performance prediction. The $\mathrm{T}$ field is located in the Malay basin and was discovered in 1979, approximately $200 \mathrm{~km}$ offshore Terengganu, Malaysia. The primary non-associated gas (NAG) accumulation in the field is found in the shallow A/B reservoirs. These reservoirs are found at approximately $700 \mathrm{~m}$ TVDss and consist of lower to middle Miocene siliciclastic sediments.

The A/B reservoirs can generally be divided into two stratigraphic units; a lower section consisting of predominantly fluvial-deltaic deposits, and an upper section consisting of subtidal bar to marginal marine deposits. The lower section is generally of higher quality $(>30 \%$ porosity, multi-Darcy permeability) relative to the upper section. However, based on 3D seismic data, the lower section is potentially more discontinuous laterally with discrete point bars indicative of potential baffles to fluid flow. Two-dimensional mapping and attribute extraction does not capture the details of these depositional elements and a volumetric approach was needed to capture these heterogeneities to condition the geological model.

\section{Methodology}

Rock property analysis using both exploration and development wells data indicates that the $\mathrm{Vp} /$ Vs ratio (ratio of compressional velocity over shear velocity) is a good lithology indicator for the A/ B reservoirs above the Gas-Water Contact (GWC). The correlation coefficient between $\mathrm{Vp} / \mathrm{Vs}$ ratio and Vclay is high. Below the GWC, there is a large overlap between the $\mathrm{Vp} / \mathrm{Vs}$ ratios of the sand and shale. Therefore $\mathrm{Vp} / \mathrm{Vs}$ ratio is not a reliable lithology indicator below the GWC. Seismic-to-well ties in the field yield high correlation coefficient (0.6-0.8) on near angle stack. These two factors suggest that inverting for $\mathrm{Vp} / \mathrm{Vs}$ ratio from seismic data could be useful in differentiating net reservoir from non-net above the GWC.

A simultaneous seismic inversion was carried out to generate the $\mathrm{Vp} / \mathrm{Vs}$ ratio volume. The $\mathrm{Vp} /$ Vs ratio volume was found to have a high linear correlation $(\mathrm{CC}=77.8 \%)$ to Vclay derived from well logs within the gas column.

The Vp/Vs ratio and seismically generated Vclay volumes were resampled into the static model framework. In the Static model domain, further interrogation was done on the resampled seismic derived Vclay volume and the FE derived Vclay from wells. The seismic derived Vclay volume was found to have a good linear correlation $(\mathrm{CC}=60 \%)$ to the $\mathrm{FE}$ derived Vclay from wells. Net rock volume above GWC was estimated using seismic-derived Vclay and specific Vclay thresholds and calibration to core lithofacies and FE derived Vclay from wells.

Porosity was modeled based on well logs using the sequential Gaussian simulation algorithm cokrigged to the seismic derived Vclay volume. The non-net rock volume that comprised of $100 \%$ shale was assumed to have $0.01 \%$ porosity. Permeability was modeled with the Sequential Gaussian simulation algorithm using a bivariate distribution of FE derived porosity and permeability crossplot. Water saturation model was based on capillary pressure and has been calculated using the Skelt-Harrison saturation function.

\section{Conclusion}

The $\mathrm{Vp} / \mathrm{Vs}$ ratio volume, inverted from simultaneous seismic inversion, has enhanced our understanding of the vertical stacking geometries and lateral distribution of lithofacies in a complex fluvial-deltaic depositional environment. This has helped to condition and build an improved geological model for flow simulation. 